\title{
Recurrent Caries at Crown Margins: Making a Decision on Treatment
}

\author{
Qasem Alomari $^{\mathrm{a}}$ Fatima Al-Saiegh ${ }^{\mathrm{c}}$ Muawia Qudeimat ${ }^{\mathrm{b}}$ Ridwaan Omar $^{\mathrm{a}}$ \\ Departments of a Restorative Sciences and ${ }^{b}$ Developmental and Preventive Sciences, Faculty of Dentistry, \\ Kuwait University, and ${ }^{\mathrm{C}}$ Ministry of Health, Kuwait
}

\begin{abstract}
Key Words
Recurrent caries, decision-making • Crown margins • Crowned tooth
\end{abstract}

\begin{abstract}
Objective: To evaluate dentists' treatment choices for a crowned tooth with varying degrees of recurrent caries. Materials and Methods: A total of 158 dentists participated in the study. A paper patient case (PPC) depicting a radiograph showing varying degrees of recurrent caries at the crown margin was used: PPC1 = small carious lesion away from crown margin; PPC2 = small carious lesion at crown margin; PPC3 = small carious lesion at crown margin extending onto the root, and PPC4 = large carious lesion at the margin; PPC5-PPC8 had the same carious conditions as PPC1-PPC4, respectively, but the teeth were non-vital. Participants were asked to indicate their choice of treatment from a list of options for each PPC. Crown removal tendency was computed after dichotomization of the responses for the different cases for each participant. Demographic information, educational background and practice characteristics were collected. Descriptive statistics, logistic regression analysis and paired-sample t test were used to analyse the data at a statistically significant level of $p<0.05$. Results: For PPC 1 and PPC5, most of the participants recommended management without crown removal ( $p<0.05)$. For PPC6, there was wide disagreement about management $(p=0.81)$. For all other PPCs, the majority of participants chose to remove the crown
\end{abstract}

(C) 2009 S. Karger AG, Basel

$1011-7571 / 09 / 0183-0187 \$ 26.00 / 0$

Fax +4161306 1234

E-Mail karger@karger.ch

www.karger.com
Accessible online at:

www.karger.com/mpp before making a treatment decision $(p<0.05)$. Logistic regression analysis showed that the size of the lesion, vitality of the tooth, participants' age as well as the undergraduate training background of dentists were factors that affected treatment decisions. Conclusion: The data showed a lack of agreement among dentists regarding the management of recurrent caries around crown margins. Size of the lesion, vitality of the tooth, educational training and experience appeared to be the main factors that affected their decisions.

Copyright $\odot 2009$ S. Karger AG, Basel

\section{Introduction}

The quality of the marginal fit of crowns is generally regarded as an important requirement for successful treatment [1]. Marginal deficiencies have been linked to fracture and dissolution of luting cement, plaque retention and secondary caries [2].

Secondary caries at the margins of crowns and fixed partial denture retainers has been reported as the most common cause of failure of such restorations [3]. While early carious lesions can cause pathological reactions of the pulpal tissues, deep lesions can additionally lead to severe destruction of hard tissues [4]. Thus, since the presence of crowns is a risk indicator for coronal and/or root caries [5], a thorough examination of the integrity of the crown margin during recall visits is essential [6]. If the margin is considered less than acceptable or suspect,

Qasem Alomari

Department of Restorative Sciences, Faculty of Dentistry, Health Sciences Centre Kuwait University

PO Box 24923, Safat 13110 (Kuwait)

Tel. +965 261 1097, Fax +965532 6049, E-Mail qalomari@hsc.edu.kw 


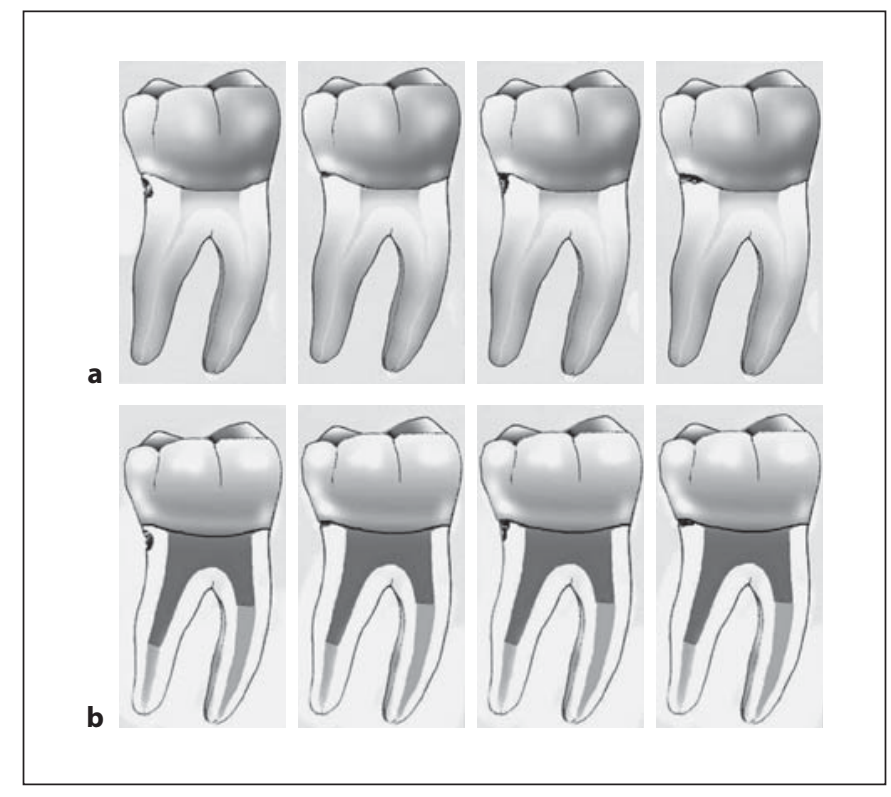

Fig. 1. Schematic representations of PPC variants for vital teeth (a, from left to right PPC1-PPC4) and non-vital teeth (b, from left to right PPC5-PPC8).

the next question that arises is the management aspect [7].

Research has shown that variations exist in the diagnoses and treatment decisions that dentists make in a variety of clinical situations $[8,9]$. Differences in clinical decision-making affect the cost-effectiveness and costbenefit of oral healthcare, with impact on both the individual patient as well as at the population level $[7,10]$ and yet they remain poorly understood [11]. Indeed, there is a perception that clinical decisions tend to be made intuitively, even idiosyncratically, and that dentists do not share a common decision-making process [12].

The factors that influence interventional approaches have been classified as dentist, practice and patient related [13]. Dentists' factors include age, experience, skills, knowledge and treatment preferences [14]. Differences in dentists' educational background [10] and levels of work experience [15] could be influential in the process. As an example, the cost of treatment was found to be more dominant than oral health status and patient preference in influencing treatment choice [16].

In Kuwait, dentists from many countries work in the oral healthcare services. These individuals are likely to have different educational and work experiences, which are factors known to be influential in clinical decisionmaking $[10,15]$. Hence, the need to investigate the asso- ciation, if any, between dentists' educational background and his/her clinical decision-making.

The aim of the study was to evaluate dentists' stated treatment choices for a series of diagrammatic representations of vital and endodontically treated teeth with artificial crowns with varying degrees of recurrent caries.

\section{Materials and Methods}

A paper patient case (PPC) depicting a 'radiograph' of a mandibular molar with a cemented artificial crown formed the basis of the investigation. Four schematic variants of the hypothetical scenario were derived from the criteria for rating secondary caries at crown margins [17], resulting in 4 qualities of the crown margin: $\mathrm{PPC} 1$ = small carious lesion away from crown margin; PPC2 = small carious lesion at crown margin; PPC3 = small carious lesion at crown margin and extending onto the root, and PPC4 = large carious lesion at the margin (fig. 1a). For each of the 4 preceding PPCs (vital teeth), the inclusion of a successful root canal treatment and post made up a further 4 variants, i.e. PPC5PPC8, respectively (fig. 1b). The same clinical history applied to each of the 8 PPC variants: 'A 45-year-old patient, who is in good general health and has a complete dentition except for third molars, attends for examination. This is your first examination of the patient. There are no clinical symptoms from the teeth or oral tissues. The "radiograph" you see was taken as part of this routine examination. The crown is 5 years old. The caries present is accessible clinically. There are no other dental problems and no further dental treatment is being planned.'

A brief questionnaire accompanied the PPCs and included the following independent variables: social variables - age and gender; educational variables - country of undergraduate education and dental specialty; current practice characteristics - workplace and area of practice. The design of the questionnaire was piloted on a group of 15 dentists who were not subsequently included in the analyses.

Sets of PPCs and questionnaires were distributed among a random sample of 158 dentists (121 males and 37 females, aged $38.7 \pm 8.7$ years, range 24-65 years) drawn from the membership of the Kuwait Dental Association, and proportionally representing all six of the governorates that make up the State of Kuwait. Participants were met in person by one of the investigators, who, after explaining the nature and aim of the study, handed them the anonymous, self-administered questionnaire and instructed them in answering questions relating to the PPCs.

Participants were instructed to address each PPC in turn and to select one of the following 5 management options for each case: 'no treatment', 'repair without removing the crown', 'remove the crown, restore caries and recement the same crown', 'remove the crown, restore caries and remake the crown', and 'extraction'. The 'progressive' nature of the options reflected the praxis concept theory [18]. Thus, it was assumed that the extent of caries at the crown margin served as stages on a health-disease continuum, whereby 'small root caries away from crown margin' and 'large carious lesion at the crown margin' were the endpoints, with the other two conditions being intervening severities. According to the praxis concept theory, it was further supposed that, in each 


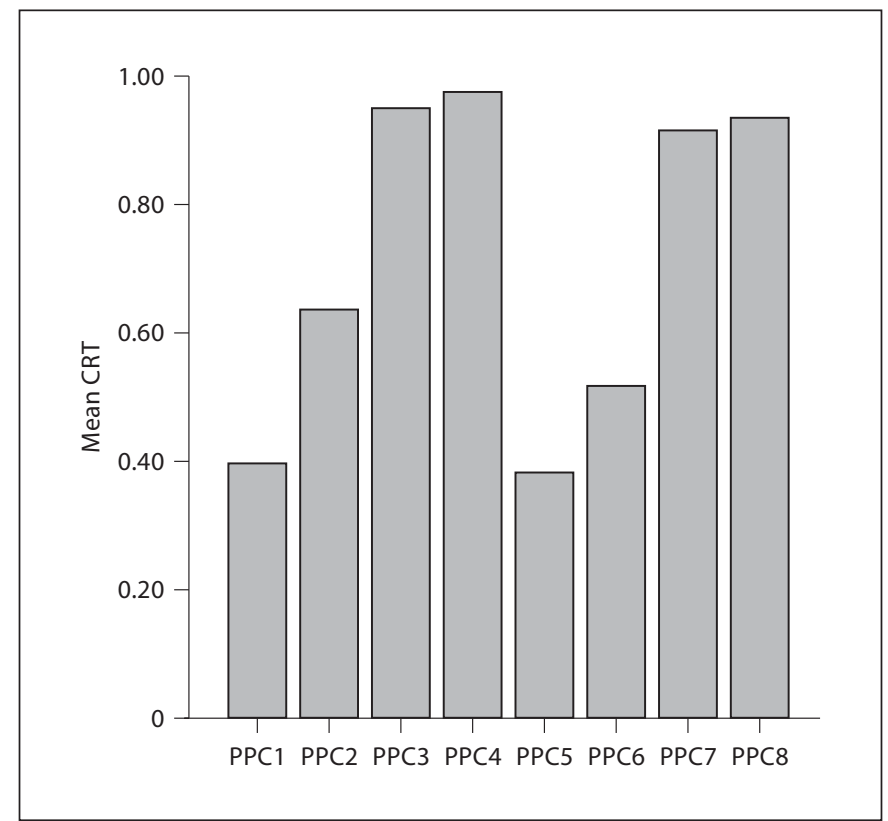

Fig. 2. Mean CRT scores for all PPCs. PPC1-PPC8 = PPCs with varying degrees of recurrent caries.

case, participants would have a personal threshold at which a distinction could be made between a decision to treat without or with crown removal. This was achieved by dichotomizing the responses into a binary dependent variable whereby a recommendation to treat without removal of the crown was set as 0 and one to remove the crown or to extract the tooth was set as 1 .

A 'crown removal tendency' (CRT) was computed as the mean of all 8 dichotomized responses for the different PPCs for each participant. The CRT score (between 0 and 1) could be interpreted as each individual's tendency for crown removal, i.e. the higher the score, the greater the tendency to remove the crown. The CRT score permitted comparisons of the tendency for crown removal according to age, gender, country of education, specialty, experience, place of work and area of work. Results were analysed using the Statistical Package for Social Sciences (SPSS, version 13.0). Descriptive statistics were calculated for all study variables. The association between the tendency to remove the crown and the different cases was expressed as odds ratios using unconditional logistic regression analysis. The paired-sample $t$ test was used to compare cases with and without root canal treatment. $\mathrm{p}<$ 0.05 was considered statistically significant.

\section{Results}

The mean CRT scores of dentists according to gender, age group, country of undergraduate education, work area and area of practice are presented in table 1 and showed no significant differences among the subgroups. General dental practitioners and prosthodontists each had a high-
Table 1. Variations in means and standard deviations (SD) of CRT scores

\begin{tabular}{|c|c|c|c|c|}
\hline & $\begin{array}{l}\text { Num- } \\
\text { ber }\end{array}$ & $\begin{array}{l}\text { Mean } \\
\text { CRT }\end{array}$ & $\mathrm{SD}$ & $\mathrm{p}$ \\
\hline \multicolumn{5}{|l|}{ Gender } \\
\hline Males & 121 & 0.69 & 0.18 & \multirow[t]{2}{*}{0.75} \\
\hline Females & 37 & 0.70 & 0.17 & \\
\hline \multicolumn{5}{|l|}{ Age } \\
\hline$\leq 35$ years & 54 & 0.69 & 0.16 & \multirow[t]{3}{*}{0.46} \\
\hline 36-49 years & 79 & 0.71 & 0.18 & \\
\hline$\geq 50$ years & 25 & 0.65 & 0.20 & \\
\hline \multicolumn{5}{|l|}{ Country of UE } \\
\hline North America & 18 & 0.64 & 0.18 & \multirow{5}{*}{0.155} \\
\hline Western Europe & 13 & 0.69 & 0.15 & \\
\hline Eastern Europe & 18 & 0.75 & 0.14 & \\
\hline Middle East & 68 & 0.73 & 0.19 & \\
\hline Asia & 41 & 0.63 & 0.16 & \\
\hline \multicolumn{5}{|l|}{ Specialty } \\
\hline General dental practitioner & 70 & 0.72 & 0.18 & \multirow[t]{3}{*}{0.08} \\
\hline Prosthodontics & 24 & 0.73 & 0.14 & \\
\hline Other specialties & 64 & 0.64 & 0.18 & \\
\hline \multicolumn{5}{|l|}{ Workplace } \\
\hline Government & 117 & 0.69 & 0.18 & \multirow[t]{2}{*}{0.84} \\
\hline Private & 41 & 0.70 & 0.16 & \\
\hline \multicolumn{5}{|l|}{ Area of practice } \\
\hline Suburban & 35 & 0.74 & 0.19 & \multirow[t]{2}{*}{0.19} \\
\hline Urban & 123 & 0.68 & 0.17 & \\
\hline Total & 158 & 0.69 & 0.18 & \\
\hline
\end{tabular}

$\mathrm{UE}=($ Dentist's $)$ undergraduate education.

er mean CRT than other specialties, and participants who received education in Eastern Europe or the Middle East had higher mean CRT scores than those who received their education in other parts of the world. However, none of these differences was statistically significant.

In general, the participants' tendency to remove the crown was greatest when the recurrent caries was large, and this was irrespective of the pulpal status (fig. 2). Frequency distributions for treatment decisions of the recurrent caries with or without crown removal for each case are presented in table 2. For PPC1 (root caries away from crown margin, vital) and PPC5 (root caries away from crown margin, non-vital) the majority of the participants (61.4 and 63.3\%, respectively) preferred to treat the lesion without removing the crown. For PPC6 (small caries at the crown margin, non-vital) there was an equal tendency among participants to treat the caries with or without removing the crown. For other cases, participants preferred to remove the crown for management. 
Table 2. Frequency distribution of participants' $(n=158)$ and recommendations for management of each PPC

\begin{tabular}{llrrr}
\hline Case & Management & Number & Percent & $\mathrm{p}$ \\
\hline \multirow{2}{*}{ PPC1 } & without crown removal & 97 & 61.4 & 0.004 \\
& with crown removal & 61 & 38.6 & \\
\hline PPC2 & without crown removal & 60 & 38.0 & 0.004 \\
& with crown removal & 98 & 62.0 & \\
\hline PPC3 & without crown removal & 11 & 7.1 & 0.000 \\
& with crown removal & 145 & 92.9 & \\
\hline PPC4 & without crown removal & 4 & 2.5 & 0.000 \\
& with crown removal & 153 & 97.5 & \\
\hline PPC5 & without crown removal & 100 & 63.3 & 0.001 \\
& with crown removal & 58 & 36.7 & \\
\hline PPC6 & without crown removal & 75 & 49.0 & 0.808 \\
& with crown removal & 78 & 51.0 & \\
\hline PPC7 & without crown removal & 15 & 9.8 & 0.000 \\
& with crown removal & 138 & 90.2 & \\
\hline PPC8 & without crown removal & 11 & 7.1 & 0.000 \\
& with crown removal & 144 & 92.9 & \\
\hline
\end{tabular}

PPC1-PPC8 = PPCs with varying degrees of recurrent caries.
The paired-sample $t$ test showed a difference in CRT between the small carious lesion on a vital tooth (PPC2) and the samelesion on a non-vital tooth (PPC6; $\mathrm{p}=0.001$ ), as well as between the large lesion on a vital tooth (PPC4) and the same lesion on a non-vital tooth (PPC8; p = 0.034). There was no difference in CRT between vital and non-vital teeth for root caries (PPC1 and PPC5) and root and crown caries (PPC3 and PPC7) when comparing vital and non-vital teeth ( $\mathrm{p}=0.55$ and 0.096 , respectively).

In the logistic regression model (table 3 ), age, country of undergraduate education, specialty and area of practice were all significantly related to the choice to restore with or without removal of the crown for PPC1, PPC2, PPC5 and PPC6. Other factors (gender, education language, workplace) had no effect on the choices expressed by participants.

Table 3. Logistic regression analysis of participants who choose to restore the tooth without removal of the crown versus those who recommended crown removal (only significant factors and cases are presented)

\begin{tabular}{|c|c|c|c|c|c|c|c|c|c|c|c|c|}
\hline \multirow[t]{2}{*}{ Variable } & \multicolumn{12}{|c|}{ Case } \\
\hline & \multicolumn{3}{|c|}{ PPC1 } & \multicolumn{3}{|c|}{ PPC2 } & \multicolumn{3}{|c|}{ PPC5 } & \multicolumn{3}{|c|}{ PPC6 } \\
\hline \multicolumn{13}{|l|}{ Age } \\
\hline$\leq 35$ years & 1.6 & $0.5-5.6$ & 0.48 & 2.6 & $0.9-8.2$ & 0.09 & & & & & & \\
\hline \multicolumn{13}{|l|}{ Country of UE } \\
\hline North America & 0.2 & $0.0-1.1$ & 0.06 & 2.2 & $0.7-7.4$ & 0.21 & 0.2 & $0.0-1.2$ & 0.83 & 2.9 & $0.9-9.7$ & 0.09 \\
\hline Western Europe & 0.6 & $0.1-2.8$ & 0.50 & 2.9 & $0.7-12.2$ & 0.15 & 0.3 & $0.1-1.9$ & 0.22 & 7.3 & $1.7-32.3$ & 0.01 \\
\hline Eastern Europe & 2.7 & $0.4-17.5$ & 0.30 & 3.0 & $0.5-18.2$ & 0.23 & 2.0 & $0.3-11.8$ & 0.47 & 2.7 & $0.4-16.7$ & 0.29 \\
\hline Middle East & 2.1 & $0.7-5.9$ & 0.18 & 3.9 & $1.4-11.2$ & 0.01 & 1.4 & $0.5-3.9$ & 0.51 & 5.1 & $1.8-14.7$ & 0.00 \\
\hline Asia (R) & - & - & - & - & - & - & - & - & - & - & - & - \\
\hline \multicolumn{13}{|l|}{ Area of practice } \\
\hline Suburban & & & & & & & & & & 2.7 & $1.1-7.1$ & 0.04 \\
\hline Urban (R) & & & & & & & & & & - & - & - \\
\hline
\end{tabular}

$\mathrm{UE}=$ Undergraduate education; $\mathrm{R}=$ reference; $\mathrm{GP}=$ general practitioner; $\mathrm{OR}=$ odds ratio; $\mathrm{CI}=$ confidence interval. $\mathrm{PPC} 1-$ PPC6 = PPCs with varying degrees of recurrent caries. 


\section{Discussion}

The clinical diagnosis of recurrent caries is an important part of general dental practice [19]. The way dentists manage such cases has implications for clinical outcomes, such as longevity and cost implications, as well as for time utilization. It is, therefore, important to analyse the available alternative treatments for restorations that have received such a diagnosis. There is a growing consensus that restorative margins that are not perfectly adapted to the prepared tooth are not per se a reason for removal of the restoration [20]. However, any reasonable suspicion of an interproximal lesion justifies more invasive diagnostic means or treatment, including the removal of the crown [6].

In this study we used radiographic simulations to describe both the extent and the location of secondary caries at or adjacent to the crown margin. The PPC method has previously been applied in similar studies $[9,18,21$, 22]. Its use permits comparisons between the present findings and the cited studies. Furthermore, the method has the advantage of reducing the background variables that a 'live' presentation might introduce [23]. On the other hand, questionnaire surveys do not measure dentists' actual clinical decisions because what people say they will do and what they actually do can be quite different [24]. Nevertheless, questionnaire responses may give a good idea of dentists' treatment philosophies [25].

In a previous study, it was reported that crowns with larger marginal gaps had a higher rating of clinically unacceptable margins as judged by both predoctoral students and prosthodontists [26]. In the present study, the larger the recurrent caries at the crown margin, the greater was the CRT prior to actual management of the lesion; it was greater among prosthodontists than among other specialties. It might be speculated that this was so because it was easier for the former group to replace the removed crown, both technically as well as perhaps economically, than for other specialists to do so.

In a study on endodontic retreatment decisions, Aryanpour et al. [27] reported that the main source of variation among dental students, endodontic staff members and instructors in 10 European dental schools was what they called the 'school effect'. In our study, the school effect became manifest as participants who had had their undergraduate dental education in Eastern Europe or in the Middle East showed the highest CRT when it was associated with recurrent caries, whereas participants who had had their undergraduate training in North America or Asia had the lowest CRT. The reason for this difference may be speculated upon: for example, regional differences are known to exist in the emphasis placed on conservatism or minimalism in restorative procedures [28], while economic factors may also be important [12]. Also, a lack of access to the current literature on the management of recurrent caries, which is predominantly published in English language journals, might be a factor. Regarding age, younger dentists were found to be more inclined towards crown removal than older colleagues. It is possible that the latter group, who are most likely to be more experienced dentists, may have a greater grasp of the need to minimize risk in complex interventions of which crown removal, especially as an attempted 'intact' procedure, may be one example [21].

The praxis concept theory, which has been discussed in the context of endodontic retreatment decision-making, states that dentists' retreatment behaviour may be explained by differences in their personal threshold at which intervention is deemed necessary along a healthdisease continuum $[18,21]$. The present findings seem to be in agreement with such a concept, in that the participants' tendency to remove the crown before treating the caries was found to increase with increasing size of the lesion. Furthermore, the majority of participants chose to remove the crown when the lesion was large and not to do so when the lesion was away from the margin of the crown. There was less uniformity among respondents when the lesion was small and at the margin, especially if the tooth had a root canal filling and post; half of them chose to remove the crown, and the other half treated the caries without removing the crown. Interestingly, even though most dentists would not want to remove the crown if the lesion was away from the margin, more than a third would remove the crown first, even if the tooth had been endodontically treated.

We found that dentists had a greater CRT in order to treat recurrent caries when the tooth was vital than when it had had root canal treatment. Although the reasons for this are not clear, it could be that dentists perceive that the risks to a vital pulp may be greater if caries removal is attempted without clear visibility of the lesion; it could also be that they considered the risks of crown removal from supposedly more weakened non-vital teeth to be too high.

Given the limitations posed by a simulated model, as well as the reliance on participants' stated intentions as regards treatment, the results of this study indicate that there is no consensus among dentists regarding the optimum management for recurrent caries at crown margins. Even when the caries was away from the margin of the 
crown, participants chose different management options, even to the extent of crown removal. The findings emphasize the need for continuing education courses and discussion in teaching institutions and dental organizations in order to develop clear guidelines for more effective management of the range of cases dentists come across in their daily clinical practice.

\section{Conclusions}

The results of this study showed a wide disparity among practitioners in the management of recurrent carious lesions at or near crown margins. Variations in the dentists' stated approaches appear to be mainly associated with age, education and training, specialty status and practice location. The presence of root canal treatment reduced the tendency of participants to remove the crown to treat recurrent caries at the margin, especially when the size of the lesion was small. Because inconsistencies in decision-making can affect the effectiveness and efficiency of patient care, more research is needed to better reconcile clinical decision-making with appropriate patient care.

\section{References}

1 Glantz PO, Nilner K, Jendresen MD, Sundberg H: Quality of fixed prosthodontics after twenty-two years. Acta Odontol Scand 2002; 60:213-218

2 Hammerle $\mathrm{CH}$ : Success and failure of fixed bridgework. Periodontol 2000 1994;4:41-51.

3 Sundh B, Odman P: A study of fixed prosthodontics performed at a university clinic 18 years after insertion. Int J Prosthodont 1997; 10:513-519.

4 Langeland K: Tissue response to dental caries. Endod Dent Traumatol 1987;3:149-171.

$\checkmark 5$ Morse DE, Holm-Pedersen P, Holm-Pedersen J, Katz RV, Viitanen M, von Strauss E, Winblad B: Prosthetic crowns and other clinical risk indicators of caries among oldold Swedish adults: findings from the KEOHS Project. Kungsholmen Elders Oral Health Study. Gerodontology 2002;19:73-79.

-6 Zoellner A, Heuermann M, Weber HP, Gaengler P: Secondary caries in crowned teeth: correlation of clinical and radiographic findings. J Prosthet Dent 2002;88:314319.

7 Omar R: The evidence for prosthodontic treatment planning for older, partially dentate patients. Med Princ Pract 2003;12(supp 1):33-42.

-8 Knutsson K, Lysell L, Rohlin M: Dentists' judgment strategies on prophylactic removal of mandibular third molars. J Dent Res 2000 79:1989-1995.

-9 Kvist T, Heden G, Reit C: Endodontic retreatment strategies used by general dental practitioners. Oral Surg Oral Med Oral Pathol Oral Radiol Endod 2004;97:502-507.
10 Marinho VC, Richards D, Niederman R: Variation, certainty, evidence, and change in dental education: employing evidence-based dentistry in dental education. J Dent Educ 2001;65:449-455.

11 Kay EJ, Blinkhorn AS: A qualitative investigation of factors governing dentists' treatment philosophies. Br Dent J 1996;180:171176.

12 Plasschaert AJ, Verdonschot EH, Wilson $\mathrm{NH}$, Blinkhorn AS: Decision making in restorative dentistry: intuition or knowledge based? Br Dent J 1995;178:320-321.

13 Kay EJ, Locker D: Variations in restorative treatment decisions: an international comparison. Community Dent Oral Epidemiol 1996;24:376-379.

14 Bader JD, Shugars DA: What do we know about how dentists make caries-related treatment decisions? Community Dent Oral Epidemiol 1997;25:97-103.

15 Omar R, Al-Kokani M, Abu Nassif L, Khan NB: Influence of dentist-related factors on the time spent on providing prosthodontic services among general dentists. Saudi Dent J 2003;15:2-10.

16 Brennan DS, Spencer AJ: Factors influencing choice of dental treatment by private general practitioners. Int J Behav Med 2002;9:94110.

17 Zoellner A, Bragger U, Fellmann V, Gaengler P: Correlation between clinical scoring of secondary caries at crown margins and histologically assessed extent of the lesions. Int J Prosthodont 2000;13:453-459.

18 Kvist T, Reit C, Esposito M, Mileman P, Bianchi S, Pettersson K, Andersson C: Prescribing endodontic retreatment: towards a theory of dentist behaviour. Int Endod J 1994;27:285-290.
19 Mjor IA: Clinical diagnosis of recurrent caries. J Am Dent Assoc 2005;136:1426-1433.

20 Mjor IA: Repair versus replacement of failed restorations. Int Dent J 1993;43:466-472.

-21 Al-Ali K, Marghalani H, Al-Yahya A, Omar $\mathrm{R}$ : An assessment of endodontic re-treatment decision-making in an educational setting. Int Endod J 2005;38:470-476.

22 Qudeimat MA, Al-Saiegh FA, Al-Omari Q, Omar R: Restorative treatment decisions for deep proximal carious lesions in primary molars. Eur Arch Paediatr Dent 2007;8:3742.

$\checkmark 23$ Bader JD, Shugars DA, McClure FE: Comparison of restorative treatment recommendations based on patients and patient simulations. Oper Dent 1994;19:20-25.

-24 Helminen SE, Vehkalati M, Murtomaa H Dentists' perception of their treatment practices versus documented evidence. Int Dent J 2002;52:71-74

25 Tveit AB, Espelid I, Skodje F: Restorative treatment decisions on approximal caries in Norway. Int Dent J 1999;49:165-172.

-26 Bronson MR, Linquist TJ, Dawson DV: Clinical acceptability of crown margins versus marginal gaps as determined by pre-doctoral students and prosthodontists. J Prosthodont 2005; 14:226-232.

-27 Aryanpour S, Van Nieuwenhuysen JP, D'Hoore W: Endodontic retreatment decisions: no consensus. Int Endod J 2000;33: 208-218

28 Elderton RJ: Changing the course of dental education to meet future requirements. J Can Dent Assoc 1997;63:633-634. 